\title{
Cl-P (Chlorine-Phosphorus)
}

\section{H. Okamoto}

[1971Chi] obtained the P-Cl phase diagram shown in Fig. 1 by differential thermal analysis of eight alloys with compositions between $\mathrm{PCl}_{3}$ and $\mathrm{PCl}_{5}$.

$\mathrm{P}-\mathrm{Cl}$ crystal structure data in Table 1 are adopted from [1973Lan].

\section{References}

1971Chi: M.K. Chikanova, D.M. Laptev, and E.S. Vorontsov: Russ. J. Inorg. Chem., 1971, vol. 16 (3), pp. 452-53.

1973Lan: Landolt-Börnstein: III7a, Crystal Structure Data of Inorganic Compounds, Springer-Verlag, Berlin, 1973.

Table 1 P-Cl crystal structure data

\begin{tabular}{lcccc}
\hline Phase & $\begin{array}{c}\text { Composition, } \\
\text { at.\% Cl }\end{array}$ & Pearson symbol & Space group & $\begin{array}{c}\text { Strukturbericht } \\
\text { designation }\end{array}$ \\
\hline $\mathrm{PCl}_{3}$ & 75 & $\ldots$ & $\ldots$ & $\ldots$ \\
$\mathrm{PCl}_{5}$ & 83.3 & $o P 24$ & $P 4 / n$ & $\ldots$ \\
\hline
\end{tabular}

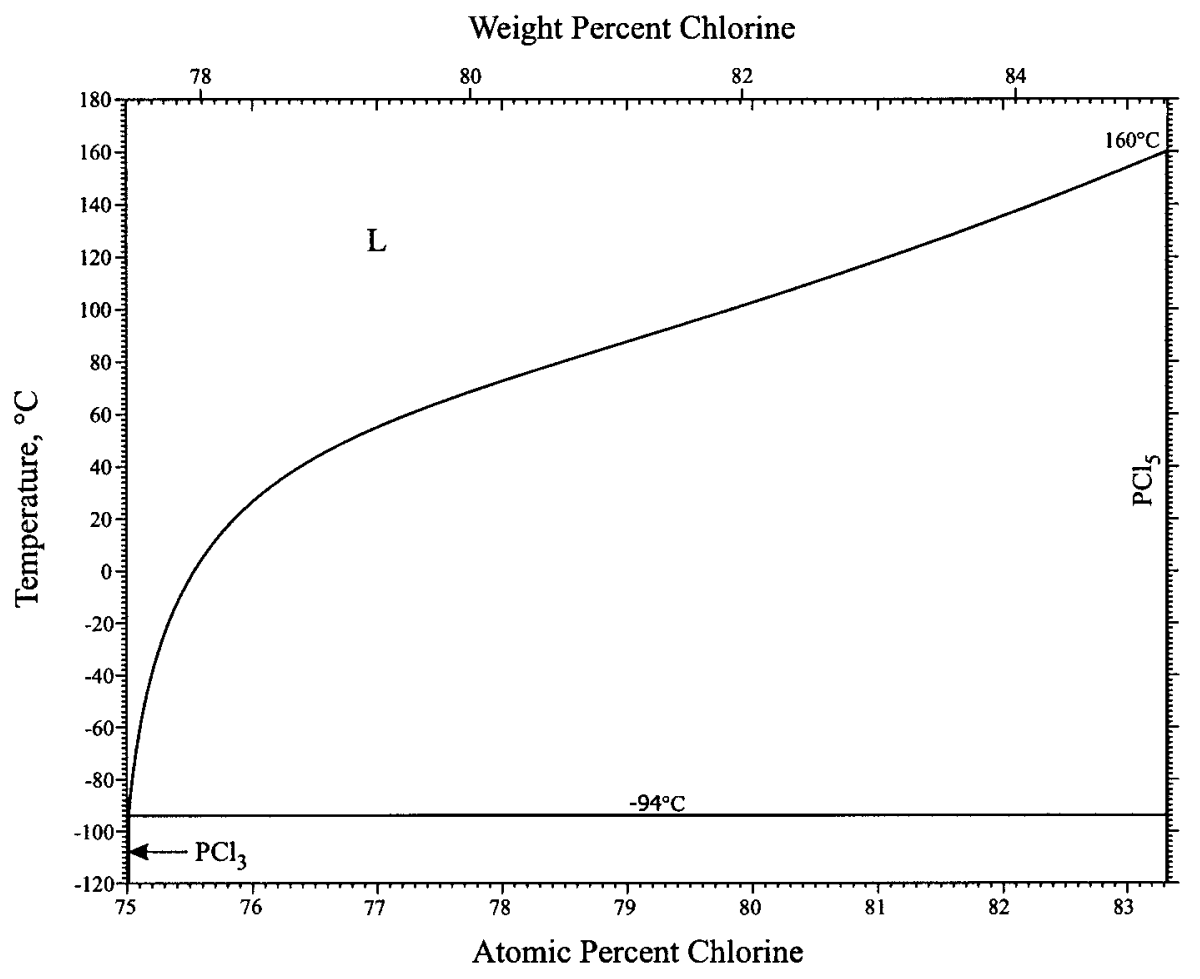

Fig. 1 Cl-P phase diagram 